\title{
Priorities of National Food Security Policy in the Russian Federation
}

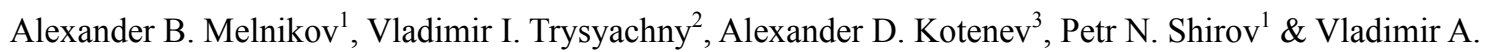 \\ Molodykh $^{4}$ \\ ${ }^{1}$ Kuban State Agrarian University, Krasnodar, Russia \\ ${ }^{2}$ Kuban State Technological University, Krasnodar, Russia \\ ${ }^{3}$ Stavropol Branch of the Krasnodar University, the Ministry of Internal Affairs of the Russian Federation, \\ Stavropol, Russia \\ ${ }^{4}$ North-Caucasian Federal University, Stavropol, Russia \\ Correspondence: Alexander B. Melnikov, Kuban State Agrarian University, Krasnodar, Russia. E-mail: \\ russia@prescopus.com
}

Received: May 7, 2018

Accepted: June 3, $2018 \quad$ Online Published: August 2, 2018

doi:10.5539/jpl.v11n3p1

URL: https://doi.org/10.5539/jpl.v11n3p1

\begin{abstract}
The influence of the globalization process on the world food market as a basic element of ensuring the domestic needs of the national economic system and affecting the level of economic security of individual states is analyzed. It is shown that the effectiveness of the import substitution policy pursued in the Russian Federation is related to the sanctions pressure and the devaluation of the national currency, while increasing the level of food security associated with self-sufficiency in basic food products is accompanied by a drop in the quality of domestic producers' products. Formation of a quality and safety management system for food products is possible within the framework of the creation of regional agro-industrial clusters, the use of which will also make it possible to apply the available technological, human and scientific and production potential more efficiently through more optimal interaction between economic agents.
\end{abstract}

Keywords: food security, import substitution, quality management, cluster, state support

\section{Introduction}

At the present stage of development, the world market of food products includes several basic components: agricultural production, processing of products and agribusiness. The first two are the basis of life support, the demand for which products sharply decreases as the market becomes saturated, and consumers' demand transfer to durable goods. The concept of "agribusiness" was first introduced into economics by J. Davis, who defined it as "a combination of operations for the production and distribution of products necessary for the supply of farms, as well as a set of industries involved in the transportation, storage, processing and distribution of agricultural products" (Davis, 1956).

The food market must ensure the existing internal needs of the national economic system, the effective functioning of which is impossible without the complex interaction of the agro-industrial complex, agribusiness entities and the logistic component where food retail chains play a leading role. The food market is primarily in relation to the rest of the markets; therefore, the violation of its work leads to a decrease in the aggregate level of economic security of a state.

It is generally accepted that the study of the global food market and the features of its functioning are based on the use of an interdisciplinary approach (Zant, 2013), since the specifics of the transformation of this market cannot be analyzed using the approaches of the neoclassical theory. The main reason for this is the need to take into account the influence of a large number of factors that have a non-economic nature: social responsibility, demographic situation, political situation, etc.

The behavior of economic agents in the world food market also requires consideration of many aspects. It is possible to note the following as the baseline:

- The theory of T. Veblen, which explains the sharp increase in demand for meat;

- Engel's law showing a reduction in the share of spending on food products with the growth of the well-being of 
a population;

- Bennett's law demonstrating that the growth of animal protein consumption directly correlates with the increase in consumer income;

- Timmer's law which shows that poor households are more sensitive to the volatility of food prices, etc.

Thus, increasing the sustainable development of the world food market is a multifaceted problem and requires a detailed analysis of various endogenous and exogenous factors that affect the level of food security of individual states and macroregions.

\section{Comparative Analysis of Forms and Methods of State Support for the Agro-Industrial Complex in Some Countries}

One of the main objectives for the development of the agro-industrial complex is to ensure an acceptable level of food security. The food security problem became particularly topical in the 70s of the twentieth century, which was caused by a total increase in the deficit of food products in developing countries. To solve these problems in 1973, the UN established a committee on food security, which has developed the corresponding concept.

The UN World Food Council defines food security as a policy that allows a country to achieve the highest level of agricultural self-sufficiency through integrated efforts to increase the production of necessary food, improve the quality of food supply and consumption, and eliminate the problem of hunger and malnutrition (http://www.fao.org).

The institutional specificity of ensuring food security implies the inability to use only market-based regulatory instruments. Analyzing the changes in the agricultural policy of European countries in the 20th century, J. Swinnen came to the conclusion that, since the $1960 \mathrm{~s}$, there has been a systematic increase in government intervention in the functioning of the agro-industrial complex in Europe, including for the protection of local producers (Swinnen Johan, 2009).

In the 1960-1970's in Japan self-sufficiency in wheat fell from $40 \%$ to $9 \%$, as during this period there was a favorable economic conjuncture in the world market, therefore imports of cheap grain poured into the country (Ito \& Krueger, 2001). However, subsequent crop failures in the exporting countries led to a sharp increase in world prices and the imposition of embargoes from those countries on the export of key types of agricultural products. As a consequence, wheat prices in Japan increased threefold during 1973, which forced the Japanese government to develop a concept for ensuring its own food security.

In South Korea, the policy of food self-sufficiency is actively pursued through the use of high tariffs and the administrative regulation of prices in key agricultural markets. As a result, as J. Begin and S. Park noted, the decrease in dependence on imports leads to significant "distortions" in the national economy, contributing to the creation of allocative effects and the flow of some additional financial resources to the agricultural sector (Beghin et al., 2003).

In Indonesia, trade policy has always been focused on the development of industrial production, and support of agro-industrial complex was expressed in a cyclic subsidizing of rice producers, the amount of which varied depending on the stage of the economic cycle (Fane G. Warr, 2014). Since the second half of the 1980s, the main mechanism for supporting local producers was a significant reduction in the level of the tax burden compared to the industrial sector.

In the US, as D. Milkovich notes, government spending on the support of the agro-industrial complex grows in proportion to the volume of agricultural production. At the same time, support was provided both for highly profitable and export-oriented crops, such as wheat, cotton and soybeans, and for low-profit crops which are mainly produced by farms (Miljkovic, 2014).

The current situation in the world food market has worsened during the crisis of 2008-2009. Its consequences are particularly negative for poor countries that are net importers of food products in international trade. However, the transformations that took place had consequences for the BRIC countries as well as for the developed countries. In some degree, this is due to the fact that the rise in prices for agricultural products leads to an increase in inflation and a decrease in the well-being of the population, which, combined with increased volatility in other global markets, ultimately leads to the emergence of a crisis in the financial market.

The exponential growth of the influence of the scientific and technical progress factor in the development of the world agro-industrial complex deserves special attention; the influence is manifested in the appearance of new crops, including the genetically modified ones, and also in the development of genetic engineering in animal husbandry, in the use of resource-saving technologies, in the production of ecologically clean products, and in 
the total increase in labor productivity.

According to J. Alston, C. Carter and V. Smith estimates, about a quarter of the world's food is redistributed through global distribution channels (Alston et al., 2013). At the same time, a dozen of the largest countries producing agricultural products form half of the world food market, acting simultaneously as importers and exporters, what once again confirms the high level of country specialization and diversification of the food assortment.

The crisis of 2008-2009 led to a stagnation in the export of food products in virtually all regions of the world and exacerbated the problem of increasing the level of economic security. For example, over the period from 2000 to 2008, there was more than threefold increase in food exports in Eastern Europe. Then, since 2009, the growth rate of exports has fallen sharply, which is partly due to the start of the implementation of the restraining agrarian policy in the EU (Strelecek \& Lososova, 2009). The countries of Latin America also almost doubled their exports of food products, what made the region the main player in the world market, but later it has also stagnated (Hennessy, 2009). However, those regions which provided the maximum increase in agricultural production, showed how unstable this growth was. In conditions of a significant reduction in prices for almost all food products during the crisis period in Eastern Europe, after the record yields, the accumulated growth potential was completely spent and by the end of 2010 the production of the main types of crops had fallen significantly. A similar situation was observed in the countries of Latin America.

Aggregate support for individual sectors of the agro-industrial complex, which, in addition to directly supporting producers, also includes subsidies to consumers, promotion of goods and infrastructure development, grew in 2006-2008 up to US \$ 368 billion, representing $0.9 \%$ of GDP of OECD countries against an average of $2.5 \%$ in the period of 1986-1998 (Miljkovic, 2014). This trend in reducing the share of support for the agro-industrial complex is primarily due to the decline in the share of agriculture in the GDP of those countries.

Modern problems associated with reducing food security are caused by a number of reasons. The real decline in prices for agricultural products, after almost continuous growth over the past thirty years, has led to a decrease in the investment attractiveness of the agro-industrial complex and subsequent stagnation in the production of food products. On the one hand, this has led to increased competitiveness of poor countries. Besides, there has been a tendency to reduce capital investment, which in the long term may lead to declining in productivity in agriculture and will not allow the necessary growth in the production of affordable products to ensure. This also creates additional incentives for the introduction of protectionist measures to protect domestic producers, what reduces the global effectiveness of the world food market.

Thus, at the present stage of development, the world food market undergoes a radical transformation which is expressed in the following:

- Methods and technologies of agricultural production and spatial characteristics of the world food market change;

- New concepts of the national policy in support of the agro-industrial complex are formed; they are aimed at increasing the level of their own food security;

- New markets for agricultural products emerge, being related, for example, to the growing demand for biofuels, increased demand for products with high added value, an increase in the share of developing countries in the world food market;

- The share of consumption of meat products increases, what did not have precedents earlier, and there is the shift of meat products production from the developed to the developing countries;

- The share of vegetables and fruits in the world food market increases, what is connected with the increase in the efficiency of supply chains, the change in diets, especially in the developed countries, and the increase in effective demand;

- International flows in the food trade change, what is associated with a change in demand for most types of products;

- Reorientation of food production with high added value to developing countries.

\section{Analysis of the Level of Food Security in the Russian Federation}

The main directions of the agro-food policy of the Russian Federation in the context of ensuring economic security are reflected in the doctrine on food security in the Russian Federation approved in 2010 (The Doctrine of Food Security of the Russian Federation, 2010). The main focus was on analyzing the issues of regulation of the agricultural products market and solving the problems on increasing the level of food security. However, 
subsequent experience has shown that the revival of the domestic agro-industrial complex requires an integrated approach which must also take into account the targets set forth in the strategy for ensuring national security until 2020, in which food security is also one of the main directions (Decree of the President of the Russian Federation, 2009).

The agro-industrial complex of the Russian Federation in the last decade has grown quite stable and fast. Thus, according to the value added index created in the agro-industrial complex, for the period from 2005 to 2014 , there was an increase in 3.3 times (Agro-industrial complex of Russia in 2014, 2014). However, despite significant growth and increase in production efficiency, domestic production in relation to subsidized imports is not competitive, what leads to its further displacement from the domestic market. This trend continues even in the context of sanctions and the growth of the cost of imports, as there is no full-fledged replacement with domestic products.

According to the opinion of a number of scientists, the ensuring of national food security requires that about $80 \%$ of agricultural production should be produced by the domestic agrarian sector (Ushachev, 2014). In this regard, the threshold indicators proposed in the Doctrine do not meet the generally accepted requirements and do not allow full achievement of the level of economic security. Thus, in accordance with the methodology developed at the Institute of Agrarian Problems of the Russian Academy of Sciences, the following indicators should be considered: the share of imports for basic foodstuffs; dynamics of agro-industrial production taking into account imported products; the share of drop-down imports; production of agricultural products per capita; availability of stock on critical food items (http://iagpran.ru/publication.php).

The experience should be considered as positive that refers to the formation of vertically integrated structures in the agroindustrial complex and restoration of positions in the world grain market. It should also be noted the decrease in dependence on meat imports down to $17 \%$ in 2014, while there is complete self-sufficiency as to pork and poultry products. In the future, the growth in production volumes for these commodity items will allow domestic producers to increase exports and take the leading positions in the world market. At present, the following situation is observed in the export of agricultural raw materials and food products. Starting from 2005, exports rose from US $\$ 4.5$ billion to US $\$ 19$ billion by 2014 , and its share in the commodity structure doubled from $1.9 \%$ to $3.8 \%$. At the same time, imports of agro-industrial products increased from US \$ 17 billion to US $\$ 40$ billion, while at the same time the share in the structure of imports fell from $17.5 \%$ to $13.9 \%$. This led to the fact that the foreign trade balance for the entire period was negative, which amounted to the US $\$ 12.5$ billion in 2005 and the US $\$ 20.9$ billion in 2014. One of the reasons for this is that average weighted growth rates of imports of agricultural products for this period amounted to $35.8 \%$, while for exports only $14.4 \%$.

In view of the current situation, we will assess the level of national food security by calculating the food dependence coefficient:

$$
K_{p b}=\frac{I}{I+P}
$$

Where

I - food imports, P - the volume of domestic food production.

The resulting values of the coefficient take the following values: safe $(0.1-0.2)$, threshold $(0.2-0.5)$, and critical (above 0.5 ). An acceptable level of food security is achieved if the share of imported food does not exceed $25 \%$. The share of imports in $30 \%$ is considered a threshold value, and exceeding $50 \%$ of the value is considered critical.

Using official data, we calculated this coefficient for the Russian Federation and the results presented in Table 1 were obtained. 
Table 1. Assessment of the national food security level

\begin{tabular}{lcccccc}
\hline Product type & \multicolumn{2}{c}{$\begin{array}{c}\text { Production } \\
\text { (kiloton) }\end{array}$} & \multicolumn{2}{c}{ Import (kiloton) } & \multicolumn{2}{c}{$\mathbf{K}_{\mathbf{p b}}$} \\
\cline { 2 - 7 } & $\mathbf{2 0 1 3}$ & $\mathbf{2 0 1 5}$ & $\mathbf{2 0 1 3}$ & $\mathbf{2 0 1 5}$ & $\mathbf{2 0 1 3}$ & $\mathbf{2 0 1 5}$ \\
\hline Beef & 1633 & 1649 & 661 & 438 & 0.29 & 0.21 \\
Pork & 2816 & 3099 & 620 & 305 & 0.18 & 0.09 \\
Poultry meat & 3831 & 4536 & 528 & 255 & 0.12 & 0.05 \\
Vegetables & 14689 & 16111 & 3000 & 2607 & 0.17 & 0.14 \\
Fruits and berries & 3381 & 3379 & 6412 & 5105 & 0.65 & 0.60 \\
Butter & 225 & 256 & 118 & 90 & 0.34 & 0.26 \\
Cheeses and cheese products & 435 & 589 & 440 & 208 & 0.50 & 0.26 \\
Milk powder & 116 & 124 & 35 & 33 & 0.23 & 0.21 \\
Sugar & 4986 & 5748 & 612 & 1010 & 0.11 & 0,15 \\
\hline
\end{tabular}

Source: http://www.gks.ru/

The results of the calculations show a significant oversupply of the domestic market with imported food products for individual commodity items, since imports provide a significant part of the effective demand of the population. The critical level of dependence is observed for fruit production, both in 2013 and in 2015, the coefficient value exceeded 0.5. The dependence on cheeses and cheese products has decreased from 0.5 to 0.26 , but this was due to the growth of domestic production of cheese products, i.e. the process of import substitution is caused by a decrease in the quality of the products. The maximum level of self-sufficiency is observed for poultry and pork meat, for other food products the value of the food dependence coefficient lies within the threshold level. At the same time, for some goods, there is a tendency for further reduction of production volumes from domestic producers, which is caused by the lack of opportunities to effectively compete with imported analogues and by reduction of the effective demand of the population for quality products. This is confirmed by the data of the foreign trade balance. Excess of exports over imports is observed only in several positions: fresh and frozen fish (951 thousand tons); wheat (21742 thousand tons); barley (3841 thousand tons); corn (3435 thousand tons); wheat flour (89.5 thousand tons); soybean oil (347 thousand tons); sunflower oil (1660 thousand tons). Thus, the increase in the level of national food security is partly due to the growth in food production of poor quality, which negatively affects the balance of the diet of the population.

\section{Improvement of Tools for Raising the Quality of Agricultural Products}

Current trends in the development of the world food market demonstrate that the use of innovative technologies in the agro-industrial complex has led to the division of the food market into several new segments: products of organic origin or environmentally friendly food, and genetically modified food. In this regard, the differentiation of world agriculture into "classical, neoclassical, genetically engineered and ecological agriculture" (Savelieva, 2013) seems very relevant. For example, from the neoclassical position, the modern agro-industrial complex is associated with a wide application of resource-saving, biotechnological and other innovative technologies (Miloserdov, 2005).

A significant increase in food imports in previous years has led to imbalances in the domestic market. The deficit of food products of domestic production is replenished by cheap imported analogs not always of high quality, which further reduces the competitiveness of domestic producers and leads to even greater growth in the deficit of domestic food. As can be seen from Table 2, the maximum level of deficit in basic foods is observed for fruits, eggs and meat. 
Table 2. Ratios of production to deficit for basic food products in Russia, kg per year per person

\begin{tabular}{lccc}
\hline \multirow{2}{*}{ Types of products } & $\begin{array}{c}\text { Production, kg per year } \\
\text { per person }\end{array}$ & kg per year per person & $\%$ \\
\cline { 3 - 4 } & 63 & 42 & 40 \\
Bread products & 86 & 53 & 39 \\
Vegetables and melons & 15 & 86 & 85 \\
Fruit & 20 & 55 & 73 \\
Meat & 225 & 115 & 34 \\
Milk & 66 & 194 & 75 \\
Eggs & & &
\end{tabular}

Source: http://iagpran.ru/publication.php

At the same time, it should be borne in mind that this deficit is associated not only with the low competitiveness of domestic products, but also with a decrease in the effective demand of the population, what leads to the replacement of high-quality products with cheap, low-quality and unsafe foodstuffs. In this regard, the growth of the quality of domestic products is the main problem that prevents the achievement of an acceptable level of national food security and requires increased attention from the state.

Improving the tools for raising the quality of food and the safety of agricultural products requires an integrated rational policy within the existing targeted programs for the development of agro-industrial clusters with the participation of government authorities of all levels, the scientific community, consumers' associations and producers of agricultural products, etc. Particular attention should be paid to the need to determine the goals and prospective tasks of the functioning of the agro-industrial cluster in the sphere of improving the quality and safety of manufactured goods, especially in the production of modern specialized therapeutic and prophylactic products (Barkhatova et al., 2000). The formation of such a system for increasing the level of food security based on the development of clusters is possible only on the basis of the implementation of generally accepted standards:

- GOST R ISO / IEC 15288-2005 "Information technology. System engineering. Processes of the life cycle of systems" (2007);

- GOST R ISO 10006-2005 "Quality management systems. Guidance on quality management in the designing" (2006);

- GOST R 52614.9-2013 "Management of sustainable development. Sustainable development management structure for business clusters" (2008).

The use of these standards in practice makes it possible to formalize a certain sequence of actions in the process of creating a system for management of quality and safety of agro-industrial products as a clearly defined algorithm. In general, the system for managing the quality and safety of agricultural products in a regional cluster consists of two control circuits (Zhigulsky, 2008): the "general quality and safety management" circuit and the "local quality and safety management" circuit, which differ in the methods and approaches, and specific tools used. The first level circuit allows an integrated approach to provide for the implementation of the stated goals for improving the level of food security, taking into account the characteristics of the products, the stages of the life cycle, the structure of an agro-industrial cluster, etc.

The scope of its action is the whole set of processes, and the object is the indicators of targeted planning and achievement of the criterial values on the basis of the used standards of management processes in the agro-cluster and the specifics of the interaction between its participants. The subject of the controlled impact is a single coordinating body for management of food products quality and safety - the Coordination Center of the Regional Agro-Industrial Cluster. The second-level contour allows the necessary level of efficiency of quality and safety management to provide not only for products, but also for necessary business processes, as well as individual managerial processes.

This management system provides a comprehensive approach to improve the quality of agricultural products in the face of negative external factors. Obviously, these circuits are closely interrelated and are in a hierarchical relationship. It is, in this connection, the methodological basis for optimizing the quality management system and the safety of agrocluster agricultural products in the context of improving food security is the use of standard 
management system design approaches, including those defined in ISO standards (Glichev, 1995).

The design and further development of a quality management system for agricultural products is based on a detailed analysis and assessment of the impact of external and internal factors on economic entities that are part of the cluster structure and identify key priorities for improving food security, as well as the need for financial, material and human resources (Kutsenko, 2010). The modernized quality management system for agricultural products is based on the need to establish a centralized cluster management body, a quality and safety coordination center, which is the highest collegial body responsible for managing and improving the quality of food products produced in the cluster. Socio-analytical and scientific and methodical sectors, the training center, the regulatory and organizational sector may act as separate structures of the management body. Being essentially a polystructural system that unites independent agricultural producers, product processors, service organizations, and public authorities in the structure of the coordinating body of an agro-industrial cluster, it can be viewed as a set of interrelated processes used to achieve the final goal, namely, to improve food security. At each hierarchical level of the agro industrial cluster, in accordance with certain activities that are directly or indirectly involved in the production of food products, the process of forming and implementing control actions that allow achieving the set goals occurs.

Thus, the structure of a regional agro-industrial cluster should be a three-dimensional model that combines its individual components into a single system based on the use of specialized management functions that comply with international standards ISO 9000, 14000, GMP principles, etc. (Gorlenko, 2002). Practical implementation of the modernization of the system aimed at increasing the level of food security on the basis of improving the quality of agricultural products manufactured in the cluster makes it possible to solve the following tasks: determining the vital processes of the agro-industrial cluster that have a decisive influence on the quality and safety of food products; search and implementation of promising tools for quality and safety management of products; definition of the circle of responsible persons; providing stakeholders with accurate and complete information about the characteristics of agricultural products.

The results of the research showed the availability of opportunities taking into account the negative influence of exogenous factors for the creation of a large-scale agro-industrial cluster in the Krasnodar Territory. This is related to the availability of a sufficiently high technical and technological, scientific and production and personnel potential, the implementation of which, taking into account the interaction between public authorities and private business, will attract additional investment resources to the promising areas of crop production. For example, as noted in the work of Barkhatova T.V. (Barkhatova, 2002), one of such areas is the processing of soybeans, modernization of morally and physically obsolete fixed assets and ensuring the final growth of the quality of agricultural products. The main factors that increase the effectiveness of the cluster are the planning horizon and close interaction between owners and management of organizations, both within the framework of contractual policy and in outsourcing to enterprises of the agro-industrial cluster not only certain types of services, but also completely technological processes.

\section{Conclusions}

The current stage of the development of the world food market undergoes a radical transformation: new segments of agricultural markets emerge, international financial and commodity flows are reoriented, and a change in the world's food ration related with increased consumption of meat products takes place. In the Russian Federation, the pressure of sanctions and increased volatility of the national currency led to the stimulation of the import substitution process in the agro-industrial complex. However, growth in self-sufficiency in basic food products and a decrease in dependence on imported analogues is accompanied by a drop in the quality of domestic manufacturers' products.

The analysis of trends in the management of quality and safety of agro-industrial products made it possible to determine that up to now there is no model of a system for managing the quality and safety of agricultural products, as well as an approach to its formation. In this regard, the proposed conceptual model of the agro-industrial cluster, allowing to provide an acceptable level of quality and safety of agricultural products at various stages of their life cycle will increase the competitiveness of domestic products, reduce dependence on imports of agricultural products, and provide an acceptable level of food security. The use of this model will create an effective system for managing the quality and safety of food products in the agro-industrial cluster and fully unleash the available technological, scientific, production and human resources. The synergetic effect from its realization is possible only due to the interaction between state authorities and private business, which will also allow additional investment resources to attract to perspective directions of manufacture of agricultural products. 


\section{References}

Agro-industrial complex of Russia in 2014. (2014). Moscow: FGBNU "Rosinformagrotekh". 605 p.

Alston, J., Carter, C., \& Smith, V. (2013). Rationalizing agricultural export subsidies. American journal of agricultural economics, 74(3).

Barkhatova, T. V., Chukhlib, V. N., \& Rylskaya, L. A. (2000). Modern medical-prophylactic products. Interregional scientific and technical seminar "Ecological safety of Russian regions". Penza. p. 93-97.

Barkhatova, T. V. (2002). Perspectives of soybean processing in the Krasnodar Territory: Textbook. Krasnodar, Publishing house KRIA, $30 \mathrm{p}$.

BE Ito, T., \& Krueger, A. O. (2001). Japan agricultural policy and protection growth. 2nd annual east Asian seminar on economics: trade and protectionism.

Beghin, J., Bureau, J., \& Park, S. (2003). Food security and agricultural protection in South Korea. American journal of agricultural economics, 85(3). https://doi.org/10.1111/1467-8276.00460

Davis, J. H. (1956). From agriculture to agribusiness. Harvard Business Review, 34(1).

Decree of the President of the Russian Federation. Dated May 12. (2009). No. 537 "On the Approval of the National Security Strategy of the Russian Federation until 2020".

Glichev, A. V. (1995). Full scheme of a product quality management mechanism. RIA "Standards and quality". No. 5. P. 53

Gorlenko, O. A. (2002). Methodology for the introduction of international standards ISO 9000. Assembly in mechanical engineering and instrument making. No. 2. P. 2-7; No. 3. P. 2-5.

GOST R 52614. 9-2013. (2008). Management of sustainable development. Structure of business clusters sustainable development management. Introduced on 01.01.2008. Moscow: Rosstandart. 57 p. (National Standard of the Russian Federation).

GOST R ISO / IEC 15288-2005. (2007). Information technology. System engineering. Processes of the life cycle of systems. Introduced on 01. 01. 2007. Moscow: Rosstandart. 57 p. (National Standard of the Russian Federation).

GOST R ISO 10006-2005. (2006). Quality management systems. Guide to quality management in the designing. Introduced on 01. 06. 2006. Moscow: Rosstandart. 28 p. (National Standard of the Russian Federation).

Hennessy, D. (2009). The production effects of agricultural income support policies under uncertainty. American journal of agricultural economics, $80(1)$.

Kutsenko, E. S. (2010). Clusters in the economy. Obozrevatel, Observer.

Miljkovic, D. (2014). Agricultural trade, commodity programs, and income protection in theUnitedthe United States. Journal of policy modeling, 26(1).

Miloserdov, V. (2005). Globalization and agriculture of Russia. Economics of agricultural and processing enterprises. No. 1. P. 9-11.

Savelieva, A. (2013). The role of the food problem in the modern world economy. Economic Journal of the Higher School of Economics, 17(3), 524-539.

Strelecek, F., \& Lososova, J. (2009). Comparison of agricultural subsidies in the Czech Republic and in theselectedthe selected states of the European Union. Agricultural economics-zemedelska ekonomika, $55(11)$.

Swinnen Johan, F. M. (2009). The Growth of Agricultural Protection in Europe in the 19th and 20th Centuries. World economy, 32(11). https://doi.org/10.1111/j.1467-9701.2009.01247.x

The Doctrine of Food Security of the Russian Federation. (2010). Approved by the Decree of the President of the Russian Federation.

Ushachev, I. (2014). Problems of Ensuring National and Collective Food Security in the EAPS. AIC: Economics, Management, (10), 3-15.

Warr, F. G. (2014). Agricultural protection in Indonesia. Bulletin of Indonesian economic studies.

Zant, W. (2013). The Impact of the Global Food Crisis on Self-Assessed Food Security. The World Bank Economic Review, (1). 
Zhigulsky, K. V. (2008). Algorithmizing the construction of a business process management system based on the project approach. Control Systems and Information Technology, (32), 354-358.

\section{Copyrights}

Copyright for this article is retained by the author(s), with first publication rights granted to the journal.

This is an open-access article distributed under the terms and conditions of the Creative Commons Attribution license (http://creativecommons.org/licenses/by/4.0/). 